\title{
Epigallocatechin Gallate in Relapsing-Remitting Multiple Sclerosis
}

\author{
A Randomized, Placebo-Controlled Trial
}

Judith Bellmann-Strobl, MD, * Friedemann Paul, MD, * Jens Wuerfel, MD, Jan Dörr, MD,

Carmen Infante-Duarte, MD, Elmira Heidrich, MD, Benedict Körtgen, MD, Alexander Brandt, MD,

Caspar Pfüller, MD, Helena Radbruch, MD, Rebekka Rust, MD, Volker Siffrin, MD, Orhan Aktas, MD,

Christoph Heesen, MD, Jürgen Faiss, MD, Frank Hoffmann, MD, Mario Lorenz, MD, Benno Zimmermann, MD,

Sergiu Groppa, MD, Klaus-Dieter Wernecke, PhD, and Frauke Zipp, MD

Neurol Neuroimmunol Neuroinflamm 2021;8:e981. doi:10.1212/NXI.0000000000000981

\section{Abstract \\ Objective}

To assess the safety and efficacy of epigallocatechin-3-gallate (EGCG) add-on to glatiramer acetate (GA) in patients with relapsing-remitting multiple sclerosis (RRMS).

\section{Methods}

We enrolled patients with RRMS (aged 18-60 years, Expanded Disability Status Scale [EDSS] score 0-6.5), receiving stable GA treatment in a multicenter, prospective, double-blind, phase II, randomized controlled trial. Participants received up to $800 \mathrm{mg}$ oral EGCG daily over a period of 18 months. The primary outcome was the proportion of patients without new hyperintense lesions on T2-weighted (T2w) brain MRI within 18 months. Secondary end points included additional MRI and clinical parameters. Immunologic effects of EGCG were investigated in exploratory experiments.

\section{Results}

A total of 122 patients on GA were randomly assigned to EGCG treatment $(n=62)$ or placebo $(\mathrm{n}=60)$. We could not demonstrate a difference between groups after 18 months for the primary outcome or other radiologic ( $\mathrm{T} 2 \mathrm{w}$ lesion volume, $\mathrm{T} 1 \mathrm{w}$ hypointense lesion number or volume, number of cumulative contrast-enhancing lesions, percent brain volume change), or clinical (EDSS, MS functional composite, and annualized relapse rate) parameter. EGCG treatment did not affect immune response to GA. Pharmacologic analysis revealed wide ranging EGCG plasma levels. The treatment was well tolerated with a similar incidence of mostly mild adverse events similar in both groups.

\section{Conclusion}

In RRMS, oral EGCG add-on to GA was not superior to placebo in influencing MRI and clinical disease activity over 18 months. The treatment was safe at a daily dosage up to $800 \mathrm{mg}$ EGCG. It did not influence immune parameters, despite indication of EGCG being bioavailable in patients.

\footnotetext{
*These authors contributed equally to this work as co-first authors.

From the NeuroCure Clinical Research Center (J.B.-S., F.P., J.D., A.B., V.S.), Charité-Universitätsmedizin Berlin; Medical Image Analysis Center (J.W.), University Basel; Institut for Medical Immunology (C.I.-D., E.H.), Charité-Universitätsmedizin Berlin; Department of Neurology and Neuroimaging Center (B.K.), Johannes Gutenberg University, Mainz; Charité-Universitätsmedizin Berlin (C.P.); NeuroCure Clinical Research Center (H.R., R.R.), Charité-Universitätsmedizin Berlin, Germany; Department of Neurology (O.A.), Medical Faculty, Heinrich Heine University Düsseldorf; Institut für Neuroimmunologie und Multiple Sklerose (C.H.), Universitätsklinikum Hamburg-Eppendorf, Hamburg; Klinik für Neurologie (J.F.), Asklepios Klinik Lübben/Teupitz; Department of Neurology (F.H.), Krankenhaus Martha-Maria Halle-Dölau, Halle/Saale; Medizinische Klinik für Kardiologie und Angiologie (M.L.), Campus Mitte, Charité-Universitätsmedizin Berlin; Institute of Nutritional and Food Sciences (B.Z.), University of Bonn; Department of Neurology and Neuroimaging Center (NIC) (S.G., F.Z.), Focus Program Translational Neuroscience (FTN), University Medical Center of the Johannes Gutenberg University, Mainz; and Charité-Universitätsmedizin Berlin and SOSTANA GmbH (K.-D.W.), Berlin.
} 


\section{Glossary}

$\mathbf{A E}=$ adverse event; $\mathbf{C E L}=$ contrast-enhancing lesion; $\mathbf{E A E}=$ experimental autoimmune encephalomyelitis; $\mathbf{E C C G}=$ epigallocatechin-3-gallate; EDSS = Expanded Disability Status Scale; GA = glatiramer acetate; $\mathbf{I T T}=$ intention to treat; $\mathbf{M S F C}=$ MS Functional Composite; NK = natural killer; PASAT = Paced Auditory Serial Addition Test; PBMC = peripheral blood mononuclear cell; PBVC = percent brain volume change; $\mathbf{P P}=$ per protocol; RRMS = relapsing-remitting MS; SAE = serious adverse event.

\section{Classification of Evidence}

This study provides Class II evidence that for patients with RRMS, EGCG added to GA did not significantly affect the development of new hyperintense lesions on T2-weighted brain MRI.

\section{Trial Registration Information}

Clinical trial registration number: NCT00525668.

Multiple sclerosis (MS) is characterized by autoimmune inflammatory and neurodegenerative pathology of the CNS causing pronounced neurologic disability in younger adults. ${ }^{1,2}$ In recent years, several immunomodulatory drugs for the treatment of relapsing-remitting MS (RRMS) have been approved targeting mainly the inflammatory processes of this disease.,

However, the development of drugs that are capable of halting or decelerating the neurodegenerative aspects, which are prevalent from the earliest disease stages, is an unmet clinical need. ${ }^{5}$

Consumption of green tea is considered to have a preventive impact on various inflammatory and neurodegenerative as well as other diseases. ${ }^{6,7}$ The most relevant compound in this regard is the polyphenol epigallocatechin gallate (EGCG), comprising $50-80 \%$ of the total catechins in green tea. ${ }^{8}$

In experimental autoimmune encephalomyelitis (EAE) —an animal model mimicking aspects of MS-EGCG exerts antiinflammatory properties via downregulation of NF- $\mathrm{kB}$ in T cells and has neuroprotective capacities by blocking the formation of neurotoxic reactive oxygen species in neurons. ${ }^{9}$ In this model, oral EGCG significantly reduced clinical disease severity as well as CNS inflammation and neuroaxonal damage, both as preventive and therapeutic treatment. ${ }^{9,10}$ Moreover, in EAE, concomitant application of EGCG and glatiramer acetate (GA) revealed synergistic effects in vitro and in vivo. ${ }^{11}$

Against this background, we investigated the effect of oral EGCG given as add-on to GA therapy over a period of 18 months on radiologic and clinical disease activity as well as safety and tolerability in patients with RRMS.

\section{Methods}

\section{Primary Research Question}

We performed a prospective, double-blind, parallel-group, randomized controlled trial in patients with RRMS, at 9 sites in Germany (including general hospitals and academic medical centers) recruiting from August 2007 to May 2011 to evaluate the question whether oral application of up to $800 \mathrm{mg}$ EGCG reduces the development of new hyperintense lesions on T2weighted (T2w) brain MRI in patients with RRMS on stable treatment with GA $20 \mathrm{mg}$. This study provides Class II evidence because less than $80 \%$ of randomized patients completed the trial.

\section{Study Design and Participants}

For details on the study conduct, refer to the study protocol in the online supplement. Eligibility criteria comprised fulfillment of the 2005 McDonald criteria for RRMS, ${ }^{12}$ age between 18 and 60 years, an Expanded Disability Status Scale (EDSS) ${ }^{13}$ score of $0-6.5$, and a stable treatment with GA $20 \mathrm{mg}$ daily subcutaneously for at least 6 months. A relapse-free period of at least 30 days before randomization was mandatory. Key exclusion criteria were any progressive forms of MS, major systemic disease, clinically relevant predefined laboratory abnormalities, and intake of any potentially hepatotoxic medication as well as cytochrome P450 3A4-inhibiting or -inducing drugs. Additional consumption of green tea or GTE was prohibited.

Because of lacking human data, sample size calculation was based on articles by Aktas et al. ${ }^{9}$ and Zhao et al. ${ }^{14}$ Proportions of $45 \%$ for EGCG and $16 \%$ for placebo were assumed for the primary end point (patients without new T2w lesions after 18 months), leading to 92 patients in total (2-sided type 1 error $=5 \%$, power $=$ $80 \%$ ). Because of uncertainty in the preconditions of the sample size calculation, an internal pilot study ${ }^{15}$ was integrated into the study. This design allows for a (blinded) recalculation of sample size without affecting the type I error. ${ }^{16}$ The planned recalculation after the inclusion of 50 participants resulted in a sample size of 126 patients in total, assuming a prior difference of 0.20 between proportions. This sample size was confirmed by a second internal blinded recalculation after inclusion of 80 individuals.

\section{Standard Protocol Approvals, Registrations, and Patient Consents}

The study was approved by the local ethics committees and by the German Federal Institute for Drugs and Medical Devices 
(BfArM). This trial is registered with EudraCT (Nr. 2006006323-39) and clinicaltrials.gov (NCT00525668). It was conducted strictly following the study protocol, the applicable German laws (Arzneimittelgesetz, 14. Novelle 2005), the Harmonized Tripartite Guideline for Good Clinical Practise (ICH-GCP), and the principles of the Declaration of Helsinki in its applicable version. Every participant provided written informed consent before enrollment.

\section{Data Availability Statement}

As far as permitted according to data protection requirements and consent provided by the participants, original data are available from the corresponding author on request from any qualified investigator within 5 years after publication.

\section{Randomization and Masking}

Patients were randomly (1:1) assigned to receive as add-on to GA after a dosing phase of 4 months per day either $800 \mathrm{mg}$ capsules of Sunphenon ${ }^{\circledR}$ (GTE containing >90\% EGCG, product of Taiyo International, taiyointernational.com) or capsules of placebo, which had identical appearance.

To account for potential baseline imbalances, patients were stratified before randomization for sex (female/male) and $\mathrm{T} 2 \mathrm{w}$ lesion number at screening ( $\leq 15$ or $>15 \mathrm{~T} 2 \mathrm{w}$ lesions). A separate block randomization list was generated by the independent pharmacy, which distributed the screened study participants to the treatment groups.

Patients and all staff remained masked for treatment allocation during the entire study. To minimize the risk of biased clinical examinations by patients reporting adverse events $(\mathrm{AE})$, an independent examining physician restricted to performing the neurologic examination rated EDSS only.

\section{Procedures}

Standardized neurologic assessments including the EDSS $^{13}$ and Multiple Sclerosis Functional Composite $(\mathrm{MSFC})^{17}$ with its subtests 9-Hole Peg Test, Timed 25-Foot Walk Test, and Paced Auditory Serial Addition Test (PASAT) were performed by an especially trained and neurostatus-certified examiner at screening (which was at most 1 week before randomization), then every 3 months until the end of the study at month 18 , and at every unscheduled visit when a relapse was suspected. A relapse was defined as any new or reoccurring neurologic symptoms in the absence of fever or infections, lasting for at least 24 hours, separated by at least 30 days from the onset of a previous relapse, and confirmed by the independent EDSS rater. For safety monitoring, regular medical examinations und laboratory examinations (blood count, liver enzymes, electrolytes, creatinine, C-reactive protein, blood glucose, and coagulation) were scheduled every 3 months and in short-term follow-up in case of pathologic results.

MRI was performed at screening and thereafter every 3 months until the end of the study at month 18 . For all study sites, MRI measurements were performed at a single central facility (leading study site Charité) ensuring identical and constant acquisition conditions on a 1.5 T MRI (Siemens Sonata, Siemens Medical Systems, Erlangen, Germany).

To investigate potential immunologic effects of EGCG treatment, we analyzed the frequencies and activation status of $\mathrm{T}$ cells $\left(\mathrm{CD} 4^{+}\right.$and $\left.\mathrm{CD} 8^{+}\right)$, B cells, monocytes, and natural killer (NK) cells by flow cytometry analysis using EDTA whole blood samples from a randomly selected subgroup of 35 study participants (20 EGCG and 15 placebo). Furthermore, to assess the specific proliferative response to GA, peripheral blood mononuclear cells (PBMCs) were isolated from patients' whole blood ( $\mathrm{n}=40$ EGCG group; $\mathrm{n}=39$ placebo group including the 35 patients of the immunologic substudy).

To measure EGCG plasma levels, biosamples were acquired at a time point after overnight fasting and before intake of the first dose of study medication (200 mg EGCG or placebo capsule) as well as 2 hours later after a standardized breakfast. Plasma concentrations of EGCG were determined as previously described. ${ }^{18}$

\section{Outcomes}

The primary outcome was the proportion of patients without new hyperintense T2w MRI lesions within 18 months. Secondary MRI outcomes were number and volume of T2w hyperintense lesions, number and volume of T1w hypointense lesions (black holes), number of cumulative contrast-enhancing lesions (CELs), and brain atrophy quantified by percent brain volume change (PBVC). Secondary clinical outcome measurements were disability progression measured by EDSS and MSFC as well as annualized relapse rate. Immunologic effects of EGCG were assessed in exploratory experiments.

\section{Statistical Analysis}

An intention-to-treat (ITT) approach was planned as the primary analysis. In addition, a per-protocol (PP) analysis was performed, omitting patients with major protocol violations, i.e., who stopped treatment due to adverse reaction or who disregarded study procedures, defined as missing more than 2 scheduled study visits or intake of less than $90 \%$ of the study medication.

Results are expressed as arithmetic mean \pm SD, median (range), or frequencies (\%). The primary end point was assessed using the Fisher exact test. Secondary end points were tested for differences between groups by using the nonparametric (exact) Mann-Whitney test for independent groups. Differences in categorical variables were tested by the Fisher exact test.

Differences between the EGCG and placebo groups for the entire time course were assessed using nonparametric multivariate variance and covariance analyses of all longitudinal 
data in a two-factorial design. ${ }^{19}$ A $p$ value $<0.05$ was considered statistically significant. All tests of secondary end points were conducted as exploratory data analysis. Therefore, no adjustments for multiple testing were made. Numerical calculations were performed with IBM SPSS Statistics for Windows, version 21 (IBM Corp., Armonk, NY), StatXact 6 (CYTEL Software Corp., Cambridge, MA), and SAS, version 9.2 (SAS Institute, Inc., Cary, NC).

\section{Results}

One hundred fifty-eight patients were screened for eligibility, 122 of whom were enrolled in the study (figure 1). Participants were randomly assigned to receive EGCG $(n=62)$ or placebo $(n=60)$ as add-on to immunomodulatory therapy with GA. All included patients were of Caucasian ethnicity.
The 2 groups did not differ regarding baseline variables (table 1).

Ultimately, 17 patients in the EGCG group and 12 patients in the placebo group did not complete the study (figure 1). This was mainly due to personal reasons (such as relocation or the desire to become pregnant), change from GA to other disease-modifying therapy, or noncompliance of study rules (e.g., missing more than 2 visits or breaking the blinding by having the study medication analyzed by a third party). One patient in each group discontinued due to stomach and digestion complaints. In the EGCG group, 1 participant had to stop study medication because of elevated liver enzymes higher than threefold the upper limit of normal; elevated values normalized thereafter. Of the patients completing the full 18 months of study medication, 33 patients $(68.8 \%)$ on placebo and 37 patients (82.2\%) on EGCG had a compliance

Figure 1 Trial Flowchart

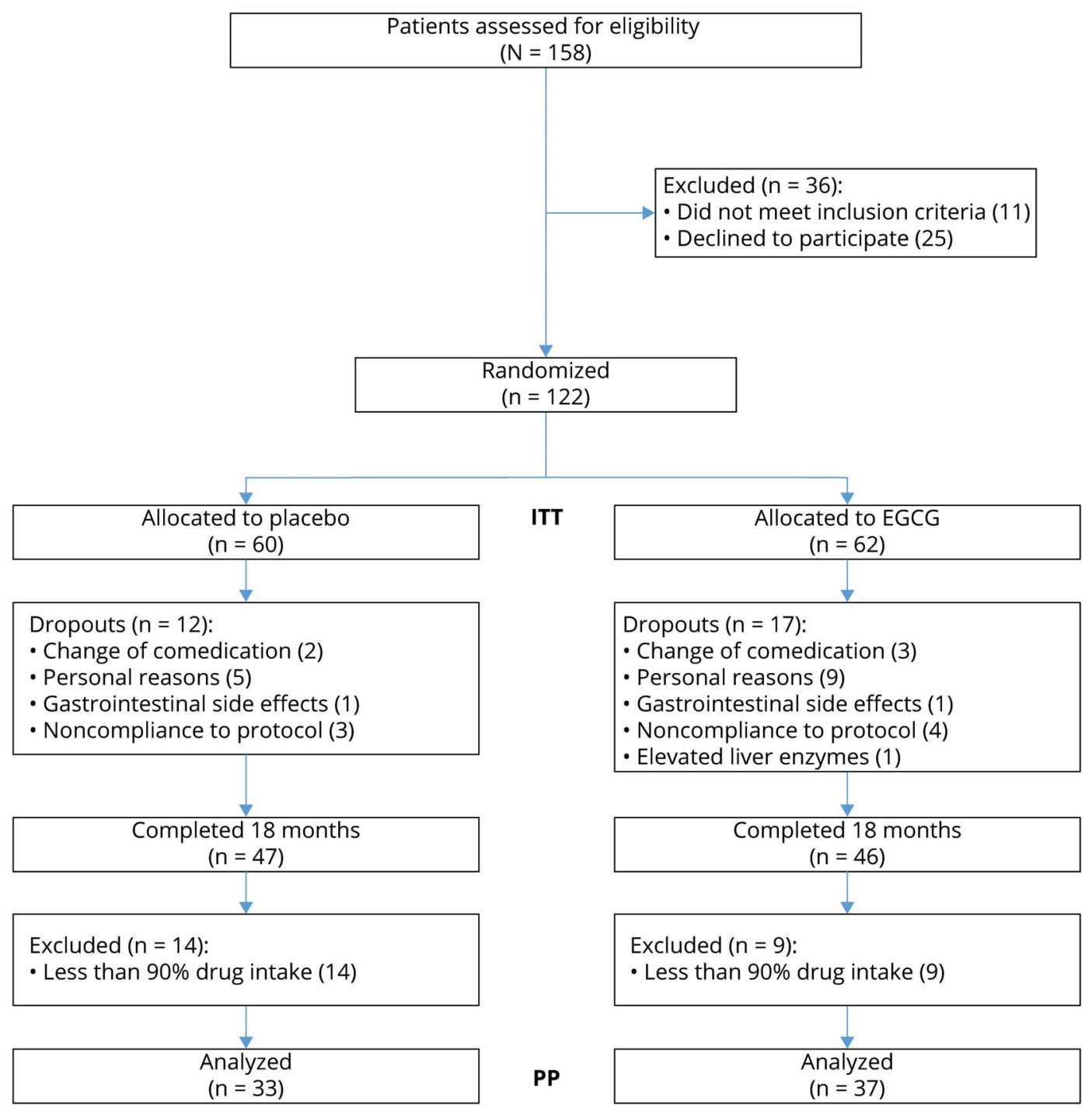

$\mathrm{ITT}=$ intention to treat; $\mathrm{PP}=$ per protocol. 
Table 1 Baseline Characteristics of the Study Population

\begin{tabular}{|c|c|c|c|}
\hline Characteristics & $\begin{array}{l}G A+E G C G \\
(n=62)\end{array}$ & $\begin{array}{l}\text { GA + placebo } \\
(n=60)\end{array}$ & $p$ Value \\
\hline Age $(y)$ & $39(9.4)^{1}$ & $42(8.0)^{c}$ & $0.060^{\mathrm{e}}$ \\
\hline Women & $41(67 \%)$ & $40(69 \%)$ & $1.000^{f}$ \\
\hline Relapse in past 12 months & $32(52 \%)$ & $36(60 \%)$ & $0.368^{f}$ \\
\hline EDSS & $2.0(0-6.0)^{d}$ & $2.0(0-6.0)^{d}$ & $0.733^{e}$ \\
\hline Time since first MS symptoms $(y)$ & $9.8(7.0)^{\mathrm{c}}$ & $8.9(6.4)^{c}$ & $0.544^{e}$ \\
\hline Time since MS diagnosis $(y)$ & $6.1(4.7)^{c}$ & $5.4(4.4)^{c}$ & $0.387^{\mathrm{e}}$ \\
\hline Duration of treatment with GA $(y)$ & $3.1(2.9)^{c}$ & $2.6(2.5)^{c}$ & $0.190^{e}$ \\
\hline Multiple Sclerosis Functional Composite (z-score) ${ }^{a}$ & $0.083(0.684)^{c}$ & $0.147(0.675)^{c}$ & $0.594^{\mathrm{e}}$ \\
\hline Paced Auditory Serial Addition Test ${ }^{a}$ & $46.8(12.4)^{\mathrm{c}}$ & $49.4(10.7)^{c}$ & $0.223^{\mathrm{e}}$ \\
\hline Timed 25-Foot Walk Test average speed (s) & $5.1(1.8)^{c}$ & $4.9(1.9)^{c}$ & $0.307^{\mathrm{e}}$ \\
\hline 9-Hole Peg Test average speed (s) & $20.7(4.3)^{c}$ & $21.5(5.6)^{c}$ & $0.884^{e}$ \\
\hline T2w lesion volume $\left(\mathrm{mm}^{3}\right)^{b}$ & $5,239(8,904)^{c}$ & $4,401(6,034)^{c}$ & $0.792^{\mathrm{e}}$ \\
\hline T2w lesion count ${ }^{b}$ & $36(33)^{c}$ & $38(28)^{c}$ & $0.443^{e}$ \\
\hline T1w hypointense lesion volume $\left(\mathrm{mm}^{3}\right)^{b}$ & $1,758(2,557)^{c}$ & $2,240(4,171)^{c}$ & $0.331^{e}$ \\
\hline T1w hypointense lesion count ${ }^{b}$ & $7(6)^{c}$ & $8(6)^{c}$ & $0.941^{\mathrm{e}}$ \\
\hline
\end{tabular}

Abbreviations: EGCG = epigallocatechin-3-gallate; EDSS = Expanded Disability Status Scale; GA = glatiramer acetate.

Data are ${ }^{\mathrm{c}}$ mean (SD), number (\%), or ${ }^{\mathrm{d}}$ median (range). ${ }^{\mathrm{e}}$ (exact) Mann-Whitney test, ${ }^{\mathrm{f}}$ Fisher exact test.

a Data available for 61 patients in the EGCG group and 59 patients in the placebo group.

b Data available for 54 patients in the EGCG group and 52 in the placebo group.

of at least $90 \%$ regarding intake of study medication (number of taken capsules as assessed by the drug count at study visits).

The results of the ITT analyses for the MRI outcome parameters are summarized in table 2 . Regarding the primary end point, we observed no significant difference in the proportion of patients without new T2w hyperintense lesions between EGCG- and placebo-treated patients at month 18 . Regarding secondary outcomes, the number of $\mathrm{T} 2 \mathrm{w}$ lesions as well as the number of $\mathrm{T} 1 \mathrm{w}$ hypointense lesions (table 2) increased irrespective of EGCG or placebo group during the study period as did the volume of $\mathrm{T} 2 \mathrm{w}$ hyperintense and $\mathrm{T} 1 \mathrm{w}$ hypointense lesions (figure 2 and table 2). Neither parameter revealed significant differences between the study groups (table 2).

Longitudinal analysis of the entire time course ${ }^{19}$ including all available time points $(0,6,12,15$, and 18 months $)$ adjusted for values at baseline also did not show a significant difference in MRI parameters between the EGCG and placebo groups (data not shown). Both groups developed a similar number of CELs during the study.

Furthermore, we could not detect a difference between the 2 study groups in PBVC, a measure of whole-brain atrophy, over the 18-month period of the trial (table 2).
With regard to clinical end points (table 3), no differences were observed in EDSS or MSFC between the EGCG and placebo groups, neither in regard to change from baseline to month 18 nor in longitudinal EDSS analysis of the entire study course adjusted for values at baseline.

The results of the PP analyses $(\mathrm{n}=70)$ concerning primary as well as all secondary outcome parameters did not differ in their statistical significance from those of the ITT analyses (data not shown).

The analysis of subgroups enables a differentiated view. In the group of participants who did not suffer a relapse 12 months before study inclusion, the rate of patients who did not develop new $\mathrm{T} 2 \mathrm{w}$ lesions was higher in the group with the active ingredient (EGCG 12/21, placebo $5 / 19, \mathrm{p}=0.062$ ). This was also the case in the group of participants with 15 and lower T2w lesions at baseline (EGCG 10/13, placebo $3 / 9, p=0.079)$ and surprisingly in the subgroup of patients who developed $\mathrm{T} 2 \mathrm{w}$ lesion volume increase during the study (EGCG $10 / 38$, placebo $3 / 35, p=0.067$ ). No statistically significant difference in the rate of newly developed T2w lesions could be demonstrated in the subgroup with EDSS 3 and lower (EGCG 13/36, placebo $11 / 39, p=0.621$ ) and in the subgroup of patients with Gd-positive lesions in the course of the study (EGCG 3/19, placebo 3/11, $p=0.641$ ). 
Table 2 MRI Outcome Parameters

\begin{tabular}{|c|c|c|c|}
\hline & GA + EGCG $(n=62)$ & GA + placebo $(n=60)$ & $p$ Value \\
\hline Proportion of patients without new T2w lesions & $18(29 \%)$ & $15(25 \%)$ & $0.686^{f}$ \\
\hline Number of new T2w lesions ${ }^{a}$ & $3.1(6.2)$ & $1.9(5.1)$ & $0.607^{\mathrm{e}}$ \\
\hline Volume of new T2w lesions $\left(\mathrm{mm}^{3}\right)^{a}$ & $749(3,639)$ & $271(1,592)$ & $0.499^{e}$ \\
\hline Number of new T1w hypointense lesions ${ }^{b}$ & $0.40(0.8)$ & $0.5(1.2)$ & $0.964^{e}$ \\
\hline Volume of new T1w hypointense lesions $\left(\mathrm{mm}^{3}\right)^{b}$ & $118(473)$ & $59(610)$ & $0.984^{\mathrm{e}}$ \\
\hline Number of CELs ${ }^{c}$ & $0.55(1.04)$ & $0.38(1.4)$ & $0.939^{\mathrm{e}}$ \\
\hline PBVC $^{d}$ & $-0.6831(0.7565)$ & $-0.5945(0.7675)$ & $0.386^{\mathrm{e}}$ \\
\hline
\end{tabular}

Abbreviations: GA = glatiramer acetate; $C E L=$ contrast-enhancing lesion; EGCG = epigallocatechin-3- gallate; PBVC = percent brain volume change. Data are mean (SD), number (\%). ${ }^{\mathrm{e}}$ (exact) Mann-Whitney test, ${ }^{\mathrm{f}}$ Fisher exact test.

a Data available for 53 patients in the EGCG group and 51 in the placebo group.

${ }^{b}$ Data available for 50 patients in the EGCG group and 51 in the placebo group.

c Data available for 42 patients in the EGCG group and 45 in the placebo group.

${ }^{\mathrm{d}}$ Data available for 42 patients in the EGCG group and 42 in the placebo group.

The analysis of the frequencies of the main immune cell populations (numbers of circulating $\mathrm{T}$ cells, $\mathrm{B}$ cells, monocytes, or NK cells) in a subgroup of 20 EGCG-treated and 15 placebo-treated patients revealed that the treatment with EGCG did not alter the overall immune status of the patients (data not shown). The in vitro examination of the $\mathrm{T}$-cell response to different concentrations of GA using PBMC from 40 EGCG and 39 placebo-treated patients indicated that treatment with EGCG did not interfere with the overall T-cell response of the patients to GA. Though, EGCG treatment had a tendency to diminish the in vitro response to high GA concentrations at $2 \mathrm{mg} / \mathrm{mL}(p=0.099$, data not shown $)$. This concentration is far higher than the serum level in humans under regular treatment with GA.

Of the 60 participants in the placebo group, 58 (97\%) experienced 1 or more AEs, with $8(13 \%)$ having a serious adverse event (SAE). In the EGCG group, 60 of the 62 participants (97\%) had at least $1 \mathrm{AE}, 6(10 \%)$ of which were considered serious (see table e-1, links.lww.com/NXI/A458). None of the SAEs were considered related to the study drug. All occurred due to hospitalization of study participants for various reasons. The incidence of $\mathrm{SAE}$ and $\mathrm{AE}$ was similar in both study groups. The most common AEs were infections of the upper respiratory, gastrointestinal, and urinary tracts. One placebo-treated and 1 EGCG-treated patient stopped intake of study medication because of gastrointestinal complaints. As 1 patient of the EGCG group had to be withdrawn due to elevated liver enzymes, we performed a comparison of liver enzyme levels between our study groups. This revealed no significant differences (data not shown). In plasma from patients on placebo, EGCG was not detectable at any time point.

In 41 patients on EGCG, 2 hours after ingestion of a standardized breakfast and the morning dose of $200 \mathrm{mg}$ Sunphenon, EGCG plasma levels ranging from 20.21 to 331.66 $\mathrm{ng} / \mathrm{mL}$ were measured. If the data set is divided into 2 groups at the median of the EGCG level, the number of new T2w lesions is less in the group with higher EGCG levels compared with the group below the median. But the numbers are too small for statistical significance.

\section{Discussion}

Our randomized, placebo-controlled multicenter study failed to show an effect of oral EGCG on MRI or clinical disease markers in patients with RRMS on stable immunomodulatory treatment with GA.

In line with other polyphenols, experimental data had previously demonstrated that orally administered EGCG reduced disease severity when given at initiation or after the onset of experimental neuroinflammation and exerted both anti-inflammatory and neuroprotective effects, also in combination with GA. ${ }^{9,11}$ Among the potential mechanisms of action of EGCG are antioxidant properties and an impact on several signal transduction pathways, including growth factor-mediated pathways, the mitogen-activated protein kinase-dependent, and ubiquitin/proteasome degradation pathways. These data in conjunction with EGCG's presumed mode of action together with the finding that the conventional form of MS typical for Western countries is much less prevalent in Asian countries with high green tea consumption like $\operatorname{Japan}^{20}$ encouraged us to conduct this randomized placebo-controlled add-on trial.

Only a few clinical studies with patients with cancer administering high-dose EGCG or GTE had been reported before planning of our trial. ${ }^{21,22}$ For the selection of the maximum daily dose of EGCG, we had to rely on pharmacokinetic and tolerability studies in healthy subjects with short-time intakes only (maximum weeks) of doses from 800 to $1,000 \mathrm{mg}$ EGCG/GTE per day. ${ }^{23-25}$ Plasma elimination half-life of 
Figure 2 T2w and T1w Hypointense Lesion Volumes

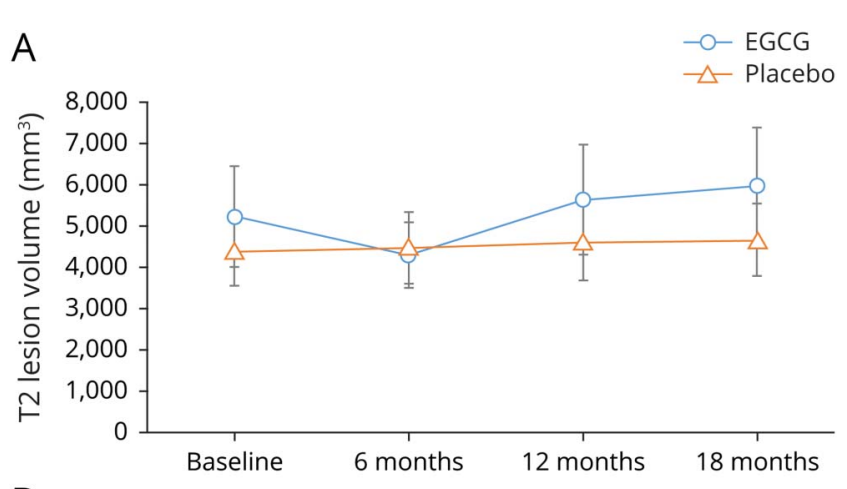

B

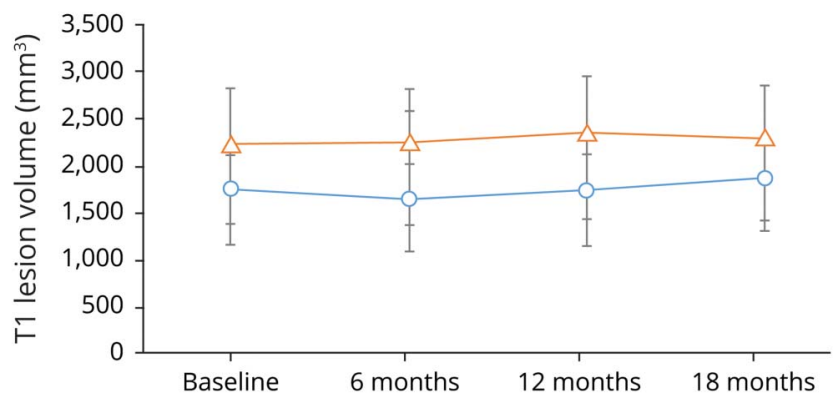

Mean change over time of volume (A) T2w lesion load (B) T1w hypointense lesion. EGCG = epigallocatechin-3-gallate.

EGCG was reported to be as long as 5.2 hours, and levels were detectable after repeated administration of $800 \mathrm{mg}$ EGCG once daily over 10 days. ${ }^{25}$ We therefore concluded that $400 \mathrm{mg}$ EGCG twice daily would be sufficient to yield measurable plasma levels even after overnight fasting. However, we have learned from our data that plasma levels of EGCG are extremely variable between individuals even under standardized conditions. Although a dosage of $600 \mathrm{mg}$ EGCG daily improved muscle metabolism in patients with $\mathrm{MS}^{26}$ oral ingestion of $400 \mathrm{mg}$ EGCG twice daily may not have been sufficient to exert biological effects in the CNS in all patients due to insufficient plasma levels. This may be 1 potential explanation for the negative outcome of this study. Recently, the bioavailability of orally administered EGCG was called into question, ${ }^{27}$ which is however in contradiction to an earlier pharmacokinetic study reporting a high absorption rate of oral EGCG in the fasting state. ${ }^{25}$

Another putative cause for not meeting the efficacy end points could lie in the add-on study design. A placebo-controlled EGCG-only trial would have been considered unethical and would not be approved by the competent authorities. Thus, we had to choose an add-on approach to an approved immunomodulatory drug. For reasons of safety, we selected GA because we considered this compound to be the least problematic in terms of potential unfavorable drug interactions, in particular as hepatotoxicity had been discussed as a rare but potentially severe side effect of green tea dietary supplements. ${ }^{28}$ Fortunately, we did not face SAEs with our EGCG dosing regimen and GA combination therapy. This is in contrast to a small study with Polyphenon E (a GTE compound) in MS that was prematurely terminated due to significant hepatotoxicity. ${ }^{29}$ In our study, only 1 subject dropped out due to elevated liver enzymes. Maybe EGCG as a pure substance afflicts metabolic processes of the liver less than GTE, containing several types of polyphenols and sometimes small amounts of caffeine in addition.

Furthermore, in the study with Polyphenon E, add-on therapy with interferon beta was permitted. Hepatotoxicity of this drug is known and may account partially for the elevation of liver enzymes reported in this study. Our trial was also safe regarding other organ-specific side effects and participants reported good overall tolerability of EGCG.

Immunologic analyses revealed no impact of EGCG on T-cell responses to GA except when applying very high doses of GA, suggesting that the study medication did not counteract the beneficial effects of GA.

In our study cohort, all patients were under stable GA treatment before administering EGCG, and only about half of the participants had suffered from a relapse during 12 months before study inclusion. This is in strong contrast to recent studies on diseasemodifying drugs in $\mathrm{MS},{ }^{30,31}$ which report a mean of 1.4 relapses in the previous 12 months, and demonstrates the notable stability of our study population. It is composed of many patients with a more benign course of MS who had a median EDSS of 2.0 at study entry after $8-9$ years of disease, making it even more difficult to observe a therapeutic effect in such patients.

As both study groups (GA + EGCG and GA + placebo) also hardly suffered from disease activity during the trial, the absence of disease dynamics made it impossible to detect an effect of the intervention.

Overestimation of the treatment effect calculating the sample size might also account for the difficulties in demonstrating mild additive or synergistic effects of EGCG.

With the given data, the power is only $7 \%$ in the ITT population to detect the difference of percentages of patients without new $\mathrm{T} 2 \mathrm{w}$ lesions between verum and placebo at the end of the study. This figure is very revealing: the small difference of percentages of patients without new T2w lesions between treatment groups in our cohort (31.9\% vs $39.1 \%$ ) can only be detected with 719 patients per group, assuming a power of $80 \%$ and a type 1 error ( $\alpha$ ) of $5 \%$ (two-sided).

These numbers seem very high for a clinical trial, but they are in the order of size of the phase III studies of the substances teriflunomide (TEMSO $\mathrm{n}=1,088$, TOWER $\mathrm{n}=1,169)^{30,32}$ and dimethyl fumarate (DEFINE $\mathrm{n}=1,237$, CONFIRM $\mathrm{n}=1,430),{ }^{30,33}$ which are now approved for the treatment of MS. The power considerations keep open the possibility of exploring, with an appropriate study design, whether the disease course of MS (at least in terms of T2 lesion load) can 
Table 3 Clinical Outcome Parameters

\begin{tabular}{|c|c|c|c|}
\hline & GA + EGCG $(n=62)$ & GA + placebo $(n=60)$ & $p$ Value \\
\hline \multicolumn{4}{|l|}{ EDSS } \\
\hline Month 18 & $2.2(1.3)$ & $2.40(1.4)$ & $0.727^{b}$ \\
\hline Change from baseline & $0.14(0.62)$ & $-0.01(0.74)$ & $0.312^{\mathrm{b}}$ \\
\hline \multicolumn{4}{|c|}{ Multiple Sclerosis Functional Composite (z-score) ${ }^{a}$} \\
\hline Month 18 & $0.34(0.72)$ & $0.40(0.56)$ & $0.931^{\mathrm{b}}$ \\
\hline Change from baseline & $-0.25(0.42)$ & $-0.26(0.32)$ & $0.772^{\mathrm{b}}$ \\
\hline \multicolumn{4}{|c|}{ Paced Auditory Serial Addition Test (z-score) $)^{a}$} \\
\hline Month 18 & $0.42(0.85)$ & $0.53(0.64)$ & $0.536^{\mathrm{b}}$ \\
\hline Change from baseline & $0.46(0.73)$ & $0.38(0.59)$ & $0.705^{\mathrm{b}}$ \\
\hline \multicolumn{4}{|l|}{ 9-Hole Peg Test (z-score) } \\
\hline Month 18 & $0.55(0.95)$ & $0.47(1.01)$ & $0.409^{b}$ \\
\hline Change from baseline & $0.39(0.55)$ & $0.45(0.53)$ & $0.701^{\mathrm{b}}$ \\
\hline \multicolumn{4}{|c|}{ Timed 25-Foot Walk Test (z-score) } \\
\hline Month 18 & $0.01(0.95)$ & $0.20(0.51)$ & $0.337^{b}$ \\
\hline Change from baseline & $-0.16(0.42)$ & $0.01(0.57)$ & $0.210^{\mathrm{b}}$ \\
\hline \multicolumn{4}{|l|}{ ARR } \\
\hline Month 18 & $0.47(0.73)$ & $0.50(0.76)$ & $0.954^{\mathrm{b}}$ \\
\hline
\end{tabular}

Abbreviations: $A R R=$ annualized relapse rate; EGCG = epigallocatechin-3-gallate; EDSS = Expanded Disability Status Scale; GA = glatiramer acetate.

Data are mean (SD). ${ }^{\mathrm{b}}$ (exact) Mann-Whitney test.

${ }^{a}$ Data available for 61 patients in the EGCG group and 59 patients in the placebo group.

be influenced by EGCG. Although the subgroup analyses only showed a statistical trend because of the small number of cases in the subgroups, it could be speculated with caution that patients with MS without relapse activity and a low cerebral lesion load could benefit from EGCG treatment.

Despite experimental evidence of anti-inflammatory and neuroprotective properties of EGCG, ${ }^{9}$ in the human setting, its neuroprotective capacities may outweigh. There is growing evidence from several case-controlled and cohort studies in North America, Europe, and Asia that consumption of tea lowers the risk of neurodegenerative disease like Alzheimer and Parkinson disease. ${ }^{34}$ However, a recently published phase III controlled clinical trial in multiple system atrophy could not reveal an association with clinically relevant disease modification compared with placebo, ${ }^{35}$ despite-also in this case-promising basic science and animal experimental data. ${ }^{36}$ Also the evaluation of PBVC - a marker for brain atrophy_-in our study could not prove an effect of EGCG on neurodegeneration within 18 months. Even with a significant extension of the study period to 36 months, no relevant effect of EGCG on the atrophy rate could be demonstrated in progressive MS. ${ }^{37}$

Recent studies reported beneficial effects of orally applied EGCG on cognitive functions in combination with cognitive training in patients with Down syndrome and fragile $\mathrm{X}$ syndrome. ${ }^{38,39}$ In our study, we assessed for the screening of cognitive function the PASAT testing calculation ability, auditory information processing speed, and flexibility. We could not reveal a positive effect of EGCG on this secondary end point. Though, our progressive MS study has provided suggestion that EGCG may have a positive effect on the test performance in PASAT. ${ }^{37}$ As cognitive decline in MS is an overwhelming and up to now unsolved problem, the effect of EGCG on improvement of cognitive function in MS should be investigated in a more sophisticated approach.

EGCG at a dose of up to $800 \mathrm{mg}$ daily was safe and well tolerated in patients with RRMS when given as add-on to GA over 18 months. However, no effect on MRI or clinical measures of disease activity could be demonstrated. Possible explanations include an underestimation of effect size in sample size calculation and insufficient EGCG dosage. Given that recent studies reported beneficial effects on cognitive functions, further investigation of EGCG in MS focused on these aspects may be warranted. Future studies should use optimized dose regimens or newer formulations of EGCG that increase bioavailability and offer an improved safety profile, in particular with regard to liver toxicity.

\section{Acknowledgment}

The authors are very grateful to all our patients who participated in this trial. They thank Michael Scheel, Susan 
Pikol, and Cynthia Kraut for technical MRI assistance as well as Bibiane Seeger for laboratory measurements. They are thankful to Taiyo International for providing us with the investigational product (Sunphenon ${ }^{\circledR}$ powder) free of charge and the foundation Artur Einstein Stiftung for donations to support the trial.

\section{Study Funding}

The study was partially funded by Taiyo International that supplied the study medication, by donations of the Artur Einstein Stiftung and by TEVA GmbH as well as by the German Research Council (DFG Exc 257 to F.Z. and F.P., CRC-TR 128 to S.G.). The sponsor of the study was Charité-Universitätsmedizin Berlin. Neither funding source nor sponsor was involved in the study design, data collection, analysis or interpretation, and in writing or in the decision to submit the manuscript.

\section{Disclosure}

J. Bellmann-Strobl reports nonfinancial support from Bayer HealthCare, grants from Biogen Idec and Merck Serono, and personal fees from TEVA GmbH, Sanofi Genzyme, Roche, and Novartis, outside the submitted work. F. Paul reports nonfinancial support from Taiyo International, grants from TEVA GmbH, and other from German Research Council (DFG), during the conduct of the study; he serves on scientific advisory boards of Novartis's OCTIMS study steering committee and MedImmune/Viela Bio steering committee; he received funding for travel or speaker honoraria from Bayer, Novartis, Biogen Idec, Teva, Sanofi-Aventis/Genzyme, Merck Serono, Alexion, Chugai, MedImmune, Shire, Roche, Actelion, and Celgene and serves on editorial boards at PLoS One (academic editor) and Neurology Neuroimmunology and Neuroinflammation (Associate Editor); he provided consultancies for Sanofi Genzyme, Biogen Idec, MedImmune, Shire, and Alexion; he received research support from Bayer, Novartis, Biogen Idec, Teva, Sanofi-Aventis/Genzyme, Alexion, Merck Serono, German Research Council (DFG Exc 257), Werth Stiftung of the City of Cologne, German Ministry of Education and Research (BMBF Competence Network MS), Arthur Arnstein Stiftung Berlin, EU FP7 Framework Program (combims.eu), Guthy Jackson Charitable Foundation, and National Multiple Sclerosis Society of the USA. J. Wuerfel has nothing to disclose. J. Dörr reports personal fees and nonfinancial support from Bayer HealthCare, Novartis, Merck, Genzyme, and Biogen and personal fees from Roche, outside the submitted work. C. Infante-Duarte, E. Heidrich, and $\mathrm{B}$. Körtgen have nothing to disclose. A. Brandt reports other from Motognosis, other from Nocturne, outside the submitted work. C. Pfüller and H. Radbruch have nothing to disclose. R. Rust reports personal fees from Roche, outside the submitted work. V. Siffrin has nothing to disclose. O. Aktas reports grants from the German Research Foundation (DFG), German Ministry of Education, Research (BMBF), Biogen, Bayer HealthCare, Sanofi Genzyme, and Novartis and personal fees from Biogen, Bayer HealthCare, Merck Serono, Novartis, Roche, Sanofi Genzyme, and Teva,

outside the submitted work. C. Heesen and J. Faiss have nothing to disclose. F. Hoffmann reports personal fees from Alexion, Biogen, Bayer, Novartis, Grifols, Merck Serono, Sanofi Genzyme, TEVA, and Roche and grants from Bayer and Novartis, outside the submitted work. M. Lorenz and B. Zimmermann have nothing to disclose. S. Groppa has no relevant disclosures. K.-D. Wernecke has nothing to disclose. F. Zipp reports grants from DFG and BMBF during the conduct of the study and consultant fees from Genzyme, Merck Serono, Roche, Novartis, Sanofi-Aventis, Celgene, ONO, and Octapharma. Go to Neurology.org/NN for full disclosures.

\section{Publication History}

Received by Neurology: Neuroimmunology \& Neuroinflammation September 16, 2020. Accepted in final form January 7, 2021.

Appendix Authors

\begin{tabular}{|c|c|c|}
\hline Name & Location & Contribution \\
\hline $\begin{array}{l}\text { Judith } \\
\text { Bellmann- } \\
\text { Strobl, MD }\end{array}$ & $\begin{array}{l}\text { Charité-Universitätsmedizin } \\
\text { Berlin, Berlin, Germany }\end{array}$ & $\begin{array}{l}\text { Major role in the } \\
\text { acquisition of data; } \\
\text { analyzed and } \\
\text { interpreted the data; } \\
\text { and drafted the } \\
\text { manuscript for } \\
\text { intellectual content }\end{array}$ \\
\hline $\begin{array}{l}\text { Friedemann } \\
\text { Paul, MD }\end{array}$ & $\begin{array}{l}\text { Charité-Universitätsmedizin } \\
\text { Berlin, Berlin, Germany }\end{array}$ & $\begin{array}{l}\text { Designed and } \\
\text { conceptualized the } \\
\text { study; major role in } \\
\text { the acquisition of } \\
\text { data; analyzed and } \\
\text { interpreted the data; } \\
\text { and drafted the } \\
\text { manuscript for } \\
\text { intellectual content }\end{array}$ \\
\hline $\begin{array}{l}\text { Jens Wuerfel, } \\
\text { MD }\end{array}$ & $\begin{array}{l}\text { University Basel, Basel, } \\
\text { Switzerland }\end{array}$ & $\begin{array}{l}\text { Designed and } \\
\text { conceptualized the } \\
\text { study; major role in } \\
\text { the acquisition of } \\
\text { data; and revised the } \\
\text { manuscript for } \\
\text { intellectual content }\end{array}$ \\
\hline Jan Dörr, MD & $\begin{array}{l}\text { Charité-Universitätsmedizin } \\
\text { Berlin, Berlin, Germany }\end{array}$ & $\begin{array}{l}\text { Designed and } \\
\text { conceptualized the } \\
\text { study; major role in } \\
\text { the acquisition of } \\
\text { data; and revised the } \\
\text { manuscript for } \\
\text { intellectual content }\end{array}$ \\
\hline $\begin{array}{l}\text { Carmen } \\
\text { Infante- } \\
\text { Duarte, PhD }\end{array}$ & $\begin{array}{l}\text { Charité-Universitätsmedizin } \\
\text { Berlin, Berlin, Germany }\end{array}$ & $\begin{array}{l}\text { Designed and } \\
\text { conceptualized the } \\
\text { study; major role in } \\
\text { the acquisition of } \\
\text { data; analyzed and } \\
\text { interpreted the data; } \\
\text { and revised the } \\
\text { manuscript for } \\
\text { intellectual content }\end{array}$ \\
\hline $\begin{array}{l}\text { Elmira } \\
\text { Heidrich, MD }\end{array}$ & $\begin{array}{l}\text { Charité-Universitätsmedizin } \\
\text { Berlin, Berlin, Germany }\end{array}$ & $\begin{array}{l}\text { Analyzed and } \\
\text { interpreted the data } \\
\text { and revised the } \\
\text { manuscript for } \\
\text { intellectual content }\end{array}$ \\
\hline
\end{tabular}


Appendix (continued)

\begin{tabular}{|c|c|c|}
\hline Name & Location & Contribution \\
\hline $\begin{array}{l}\text { Benedict } \\
\text { Körtgen, MD }\end{array}$ & $\begin{array}{l}\text { Johannes Gutenberg } \\
\text { University, Mainz, Germany }\end{array}$ & $\begin{array}{l}\text { Analyzed and } \\
\text { interpreted the data } \\
\text { and revised the } \\
\text { manuscript for } \\
\text { intellectual content }\end{array}$ \\
\hline $\begin{array}{l}\text { Alexander } \\
\text { Brandt, MD }\end{array}$ & $\begin{array}{l}\text { Charité-Universitätsmedizin } \\
\text { Berlin, Berlin, Germany }\end{array}$ & $\begin{array}{l}\text { Major role in the } \\
\text { acquisition of data; } \\
\text { analyzed and } \\
\text { interpreted the data; } \\
\text { and revised the } \\
\text { manuscript for } \\
\text { intellectual content }\end{array}$ \\
\hline
\end{tabular}

$\begin{array}{ll}\text { Caspar Pfüller, } & \text { Charité-Universitätsmedizin } \\ \text { MD } & \text { Berlin, Berlin, Germany }\end{array}$

Major role in the acquisition of data and revised the manuscript for intellectual content

\begin{tabular}{lll}
\hline Helena & Charité-Universitätsmedizin & Major role in the \\
Radbruch, MD & Berlin, Berlin, Germany & $\begin{array}{l}\text { acquisition of data } \\
\text { and revised the } \\
\text { manuscript for } \\
\end{array}$ \\
& intellectual content
\end{tabular}

\begin{tabular}{ll}
\hline Rebekka Rust, & Charité-Universitätsmedizin \\
MD & Berlin, Berlin, Germany
\end{tabular}

Analyzed and interpreted the data and revised the manuscript for intellectual content

\begin{tabular}{ll}
\hline Volker Siffrin, & Charité-Universitätsmedizin \\
MD & Berlin, Berlin, Germany
\end{tabular}

Major role in the acquisition of data and revised the manuscript for intellectual content

\begin{tabular}{lll}
\hline Orhan Aktas, & Heinrich Heine University & Designed and \\
MD & Düsseldorf, Düsseldorf, & conceptualized the \\
& Germany & study; major role in \\
& the acquisition of \\
& data; and revised \\
& the manuscript for \\
& intellectual content
\end{tabular}

\begin{tabular}{|c|c|c|}
\hline $\begin{array}{l}\text { Christoph } \\
\text { Heesen, MD }\end{array}$ & $\begin{array}{l}\text { Universitätsklinikum } \\
\text { Hamburg- Eppendorf, } \\
\text { Hamburg, Germany }\end{array}$ & $\begin{array}{l}\text { Major role in the } \\
\text { acquisition of data } \\
\text { and revised the } \\
\text { manuscript for } \\
\text { intellectual content }\end{array}$ \\
\hline $\begin{array}{l}\text { Jürgen Faiss, } \\
\text { MD }\end{array}$ & $\begin{array}{l}\text { Asklepios Klinik Lübben/ } \\
\text { Teupitz, Teupitz, Germany }\end{array}$ & $\begin{array}{l}\text { Major role in the } \\
\text { acquisition of data } \\
\text { and revised the } \\
\text { manuscript for } \\
\text { intellectual content }\end{array}$ \\
\hline $\begin{array}{l}\text { Frank } \\
\text { Hoffmann, MD }\end{array}$ & $\begin{array}{l}\text { Krankenhaus Martha-Maria } \\
\text { Halle-Dölau, Halle (Saale), } \\
\text { Germany }\end{array}$ & $\begin{array}{l}\text { Major role in the } \\
\text { acquisition of data } \\
\text { and revised the } \\
\text { manuscript for } \\
\text { intellectual content }\end{array}$ \\
\hline $\begin{array}{l}\text { Mario Lorenz, } \\
\text { PhD }\end{array}$ & $\begin{array}{l}\text { Charité-Universitätsmedizin } \\
\text { Berlin, Berlin, Germany }\end{array}$ & $\begin{array}{l}\text { Designed and } \\
\text { conceptualized the } \\
\text { study; interpretation } \\
\text { of data; and revised } \\
\text { the manuscript for } \\
\text { intellectual content }\end{array}$ \\
\hline $\begin{array}{l}\text { Benno } \\
\text { Zimmermann, } \\
\text { MD }\end{array}$ & $\begin{array}{l}\text { Rheinische Friedrich- } \\
\text { Wilhelms-Universität Bonn, } \\
\text { Bonn, Germany }\end{array}$ & $\begin{array}{l}\text { Analyzed and } \\
\text { interpreted the data } \\
\text { and revised the } \\
\text { manuscript for } \\
\text { intellectual content }\end{array}$ \\
\hline
\end{tabular}

Appendix (continued)

\begin{tabular}{|c|c|c|}
\hline Name & Location & Contribution \\
\hline $\begin{array}{l}\text { Sergiu Groppa, } \\
\text { MD }\end{array}$ & $\begin{array}{l}\text { Johannes Gutenberg } \\
\text { University, Mainz, Germany }\end{array}$ & $\begin{array}{l}\text { Analyzed and } \\
\text { interpreted the data } \\
\text { and revised the } \\
\text { manuscript for } \\
\text { intellectual content }\end{array}$ \\
\hline $\begin{array}{l}\text { Klaus-Dieter } \\
\text { Wernecke, } \\
\text { PhD }\end{array}$ & $\begin{array}{l}\text { Charité-Universitätsmedizin } \\
\text { Berlin, Berlin, Germany }\end{array}$ & $\begin{array}{l}\text { Designed and } \\
\text { conceptualized the } \\
\text { study; analyzed the } \\
\text { data; and drafted the } \\
\text { manuscript for } \\
\text { intellectual content }\end{array}$ \\
\hline $\begin{array}{l}\text { Frauke Zipp, } \\
\text { MD }\end{array}$ & $\begin{array}{l}\text { Johannes Gutenberg } \\
\text { University, Mainz, Germany }\end{array}$ & $\begin{array}{l}\text { Designed and } \\
\text { conceptualized the } \\
\text { study; interpreted } \\
\text { data; and revised the } \\
\text { manuscript }\end{array}$ \\
\hline
\end{tabular}

\section{References}

1. Zipp F, Gold R, Wiendl H. Identification of inflammatory neuronal injury and prevention of neuronal damage in multiple sclerosis: hope for novel therapies? JAMA Neurol 2013;70:1569-1574

2. Frischer JM, Bramow S, Dal-Bianco A, et al. The relation between inflammation and neurodegeneration in multiple sclerosis brains. Brain 2009;132:1175-1189.

3. Dörr J, Paul F. The transition from first-line to second-line therapy in multiple sclerosis. Curr Treat Options Neurol 2015;17:25.

4. Wingerchuk DM, Weinshenker BG. Disease modifying therapies for relapsing multiple sclerosis. BMJ 2016;354:i3518.

5. Fazekas F. Where to go next with neuroprotection in multiple sclerosis? Lancet Neurol 2010;9:647-648.

6. Morinobu A, Biao W, Tanaka S, et al. (-)-Epigallocatechin-3-gallate suppresses osteoclast differentiation and ameliorates experimental arthritis in mice. Arthritis Rheum 2008;58:2012-2018.

7. Noratiqah S, Naina-Mohamed I, Zulfarina M, Qodriyah H. Natural polyphenols in the treatment of Alzheimer's disease. Curr Drug Targets 2017;18:1.

8. Ashihara H, Deng WW, Mullen W, Crozier A. Distribution and biosynthesis of flavan3-ols in Camellia sinensis seedlings and expression of genes encoding biosynthetic enzymes. Phytochemistry 2010;71:559-566.

9. Aktas O, Prozorovski T, Smorodchenko A, et al. Green tea epigallocatechin-3-gallate mediates $\mathrm{T}$ cellular NF-kappa B inhibition and exerts neuroprotection in autoimmune encephalomyelitis. J Immunol 2004;173:5794-5800.

10. Sun $\mathrm{Q}$, Zheng $\mathrm{Y}$, Zhang X, et al. Novel immunoregulatory properties of EGCG on reducing inflammation in EAE. Front Biosci (Landmark Ed) 2013;18:332-342.

11. Herges K, Millward JM, Hentschel N, Infante-Duarte C, Aktas O, Zipp F. Neuroprotective effect of combination therapy of glatiramer acetate and epigallocatechin-3gallate in neuroinflammation. PLoS One 2011;6:e25456.

12. McDonald WI, Compston A, Edan G, et al. Recommended diagnostic criteria for multiple sclerosis: guidelines from the international panel on the diagnosis of multiple sclerosis. Ann Neurol 2001;50:121-127.

13. Kurtzke JF. Rating neurologic impairment in multiple sclerosis: an expanded disability status scale (EDSS). Neurology 1983;33:1444.

14. Zhao G, Koopmans R, Li D, Bedell L, Paty DW. Effect of interferon beta-1b in MS: assessment of annual accumulation of PD/T2 activity of MRI. Neurology 2000;54 200-206.

15. Friede T, Kieser M. Sample size recalculation for binary data in internal pilot study designs. Pharm Stat 2004;3:269-279.

16. Kieser M, Friede T. Simple procedures for blinded sample size adjustment that do not affect the type I error rate. Stat Med 2003;22:3571-3581.

17. Fischer JS, Rudick RA, Cutter GR, Reingold SC. The Multiple Sclerosis Functional Composite measure (MSFC): an integrated approach to MS clinical outcome assessment. Mult Scler J 1999;5:244-250.

18. Lorenz M, Paul F, Moobed M, et al. The activity of catechol-O-methyltransferase (COMT) is not impaired by high doses of epigallocatechin-3-gallate (EGCG) in vivo. Eur J Pharmacol 2014;740:645-651.

19. Brunner E, Domhof S, Langer F. Nonparametric Analysis of Longitudinal Data in Factorial Experiments. J. Wiley; 2002. Available at: books.google.de/books/about/ Nonparametric_analysis_of_longitudinal_d.html?i d=UxzvAAAAMAAJ\&redir_esc=y. Accessed February 12, 2018.

20. Kira J. Multiple sclerosis in the Japanese population. Lancet Neurol 2003;2:117-127.

21. Pisters KM, Newman RA, Coldman B, et al. Phase I trial of oral green tea extract in adult patients with solid tumors. J Clin Oncol 2001;19:1830-1838.

22. Bettuzzi S, Brausi M, Rizzi F, Castagnetti G, Peracchia G, Corti A. Chemoprevention of human prostate cancer by oral administration of green tea catechins in volunteers 
with high-grade prostate intraepithelial neoplasia: a preliminary report from a oneyear proof-of-principle study. Cancer Res 2006;66:1234-1240.

23. Unno T, Kondo K, Itakura H, Takeo T. Analysis of (-)-epigallocatechin gallate in human serum obtained after ingesting green tea. Biosci Biotechnol Biochem 1996;60:2066-2068.

24. Lee MJ, Wang ZY, Li H, et al. Analysis of plasma and urinary tea polyphenols in human subjects. Cancer Epidemiol Biomarkers Prev 1995;4:393-399.

25. Ullmann U, Haller J, Decourt JD, Girault J, Spitzer V, Weber P. Plasma-kinetic characteristics of purified and isolated green tea catechin epigallocatechin gallate (EGCG) after 10 days repeated dosing in healthy volunteers. Int J vitamin Nutr Res 2004;74:269-278.

26. Mähler A, Mandel S, Lorenz M, et al. Epigallocatechin-3-gallate: a useful, effective and safe clinical approach for targeted prevention and individualised treatment of neurological diseases? EPMA J 2013;4:5.

27. Chakrawarti L, Agrawal R, Dang S, Gupta S, Gabrani R. Therapeutic effects of EGCG: a patent review. Expert Opin Ther Patents 2016;26:907-916.

28. Bonkovsky HL. Hepatotoxicity associated with supplements containing Chinese green tea (Camellia sinensis). Ann Intern Med 2006;144:68-71.

29. Lovera J, Ramos A, Devier D, et al. Polyphenon E, non-futile at neuroprotection in multiple sclerosis but unpredictably hepatotoxic: phase I single group and phase II randomized placebo-controlled studies. J Neurol Sci 2015;358:46-52.

30. O'Connor P, Wolinsky JS, Confavreux C, et al. Randomized trial of oral teriflunomide for relapsing multiple sclerosis. N Engl J Med 2011;365:1293-1303.

31. Fox RJ, Miller DH, Phillips JT, et al. Placebo-controlled phase 3 study of oral BG-12 or glatiramer in multiple sclerosis. N Engl J Med 2012;367:1087-1097.
32. Confavreux C, O'Connor P, Comi G, et al. Oral teriflunomide for patients with relapsing multiple sclerosis (TOWER): a randomised, double-blind, placebocontrolled, phase 3 trial. Lancet Neurol 2014;13:247-256.

33. Gold R, Kappos L, Arnold DL, et al. Placebo-controlled phase 3 study of oral BG-12 for relapsing multiple sclerosis. N Engl J Med 2012;367:1098-1107.

34. Singh NA, Mandal AKA, Khan ZA. Potential neuroprotective properties of epigallocatechin-3-gallate (EGCG). Nutr J 2016;15:60.

35. Levin J, Maaß S, Schuberth M, et al. Safety and efficacy of epigallocatechin gallate in multiple system atrophy (PROMESA): a randomised, double-blind, placebocontrolled trial. Lancet Neurol 2019;18:724-735.

36. Dehay B, Bourdenx M, Gorry P, et al. Targeting $\alpha$-synuclein for treatment of Parkinson's disease: mechanistic and therapeutic considerations. Lancet Neurol 2015;14 855-866.

37. Rust $\mathrm{R}$, Chien $\mathrm{C}$, Scheel $\mathrm{M}$ et al. Epigallocatechin- gallate in progressive multiple sclerosis: a randomized, placebo-controlled trial. Neurol Neuroimmunol Neuroinflamm 2021;8:e964.

38. de la Torre R, de Sola S, Hernandez G, et al. Safety and efficacy of cognitive training plus epigallocatechin-3-gallate in young adults with Down's syndrome (TESDAD): a double-blind, randomised, placebo-controlled, phase 2 trial. Lancet Neurol 2016;15: 801-810.

39. de la Torre R, de Sola S, Farré M, et al. A phase 1, randomized double-blind, placebo controlled trial to evaluate safety and efficacy of epigallocatechin-3-gallate and cognitive training in adults with Fragile X syndrome. Clin Nutr 2020;39:378-387. 


\title{
Neurology ${ }^{\oplus}$ \\ Neuroimmunology \& Neuroinflammation
}

\author{
Epigallocatechin Gallate in Relapsing-Remitting Multiple Sclerosis: A Randomized, \\ Placebo-Controlled Trial \\ Judith Bellmann-Strobl, Friedemann Paul, Jens Wuerfel, et al. \\ Neurol Neuroimmunol Neuroinflamm 2021;8; \\ DOI 10.1212/NXI.0000000000000981
}

This information is current as of March 24, 2021

Neurol Neuroimmunol Neuroinflamm is an official journal of the American Academy of Neurology.

Published since April 2014, it is an open-access, online-only, continuous publication journal. Copyright

Copyright (C) 2021 The Author(s). Published by Wolters Kluwer Health, Inc. on behalf of the American

Academy of Neurology.. All rights reserved. Online ISSN: 2332-7812.

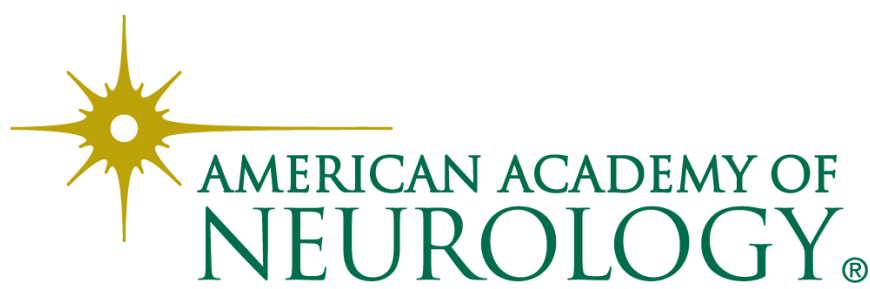




\section{Updated Information \& Services}

References

Subspecialty Collections

Permissions \& Licensing

Reprints including high resolution figures, can be found at:

http://nn.neurology.org/content/8/3/e981.full.html

This article cites 38 articles, 6 of which you can access for free at: http://nn.neurology.org/content/8/3/e981.full.html\#\#ref-list-1

This article, along with others on similar topics, appears in the following collection(s):

\section{Autoimmune diseases}

http://nn.neurology.org//cgi/collection/autoimmune_diseases

\section{Class II}

http://nn.neurology.org//cgi/collection/class_ii

Clinical trials Randomized controlled (CONSORT agreement)

http://nn.neurology.org//cgi/collection/clinical_trials_randomized_cont rolled_consort_agreement

\section{MRI}

http://nn.neurology.org//cgi/collection/mri

Multiple sclerosis

http://nn.neurology.org//cgi/collection/multiple_sclerosis

Information about reproducing this article in parts (figures,tables) or in its entirety can be found online at:

http://nn.neurology.org/misc/about.xhtml\#permissions

Information about ordering reprints can be found online:

http://nn.neurology.org/misc/addir.xhtml\#reprintsus

Neurol Neuroimmunol Neuroinflamm is an official journal of the American Academy of Neurology.

Published since April 2014, it is an open-access, online-only, continuous publication journal. Copyright

Copyright $\odot 2021$ The Author(s). Published by Wolters Kluwer Health, Inc. on behalf of the American Academy of Neurology.. All rights reserved. Online ISSN: 2332-7812.

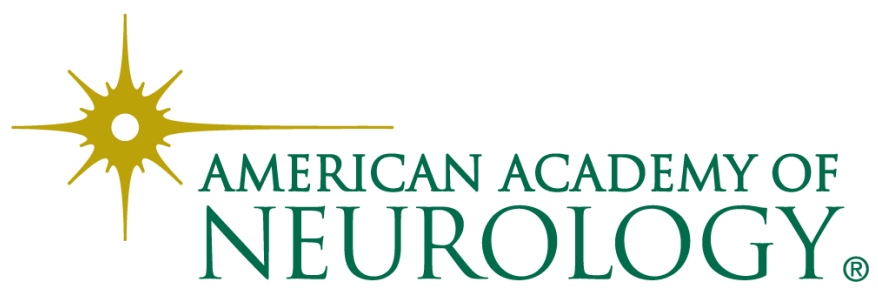

